\title{
Natural infection of Didelphis aurita (Mammalia: Marsupialia) with Leishmania infantum in Brazil
}

João Carlos Araujo Carreira', Alba Valéria Machado da Silva², Daniela de Pita Pereira ${ }^{3}$ and Reginaldo Peçanha Brazil ${ }^{4^{*}}$

\begin{abstract}
Background: The opossum Didelphis have been considered as natural hosts of Leishmania parasites in the New World, suggesting an important role in the epidemiology of Visceral Leishmaniasis (VL). Among six extant species that belong to the genus Didelphis, only two (D. marsupialis and D. albiventris), have been mentioned as natural hosts of Leishmania infantum in Brazil and Colombia. In the present paper, it is reported for the first time, the observation of intracellular parasites (amastigotes) in tissues of Didelphis aurita naturally infected with Leishmania infantum in Brazil. We also discuss some aspects associated to the relationship between $L$. infantum and the geographical distribution of some species of the genus Didelphis.
\end{abstract}

Methods: The opossums studied were caught by wire traps (Tomahawk) in Barra de Guaratiba, a peri-urban area in Rio de Janeiro. The opossums were killed with an overdose of Thiopental sodium.At necropsy, macroscopic alterations were examined and samples from liver, spleen, lymph nodes, ear, abdominal skin, scent glands and bone marrow were collected for parasitological and molecular diagnoses.

Results: Forty-eight opossums were captured in an AVL endemic region, 30 being caught in a mangrove area and eighteen animals in a forest area near to some residential-yards. Among the thirty opossums trapped in the mangrove area, all of them were negative by both imprint and sera samples assayed on Dipstick Tests, that is a test based on a combination of protein-A colloidal gold conjugate and rk39 Leishmania antigen to detect antiLeishmania antibody in serum or plasma. At the macroscopic examination one out of eighteen opossums, caught close to the forest, presented alterations compatible with spleen hypertrophy and three were positive by Dipstick Tests (16.6\%) and presented amastigotes in the spleen and in one of them, the parasites were also observed in a submandibular lymph node. Leishmania infantum infections were confirmed through dot blot hybridization using a L. infantum-specific biotinylated probe.

Conclusions: In the present paper we present the first report of amastigotes in the tissues of Didelphis aurita (Mammalia: Marsupialia) naturally infected with Leishmania infantum. We also attempt to claim the particular role of some opossum species as hosts of Leishmania infantum, contributing at least in part on the description of potential sylvatic reservoirs.

Keywords: Didelphis aurita, Leishmania infantum, Tissular parasitism, Amastigotes

\footnotetext{
* Correspondence: rpbrazil@ioc.fiocruz.br

${ }^{4}$ Laboratório de Bioquímica e Fisiologia de Insetos, Instituto Oswaldo

Cruz/Fiocruz, Avenida Brasil, 4365, Rio de Janeiro, RJ CEP 21045-900, Brazil

Full list of author information is available at the end of the article
} 


\section{Background}

Domestic and sylvatic canids are considered the most important reservoirs of Leishmania infantum in America $[1,2]$. Nevertheless, under certain conditions the opossums of the genus Didelphis could play an important part in the maintainance of the parasite, Leishmania infantum, due to its ability to live in different habitats providing a link between the wild and domestic cycles of the disease [3].

Likewise in urban endemic areas of leishmaniasis, where the majority of sylvatic mammals are not normally found, the opossums may also assume a very important role in the epidemiology of the disease.

The species Didelphis albiventris was the first noncanid wild mammal to be described as naturally infected with Leishmania infantum in the New World [4]. In this same study, it was also reported that Lutzomyia longipalpis, the main vector of the parasite in the New World, was capable of feeding on this species. At a later date, L. infantum was isolated from two Didelphis albiventris, which had been caught by trapping in a focus of American Visceral Leishmaniasis (AVL) in Bahia, Brazil [5].

Corredor et al. (1989) [6], working in one focus of AVL in Colombia observed that the infection-rate of the opossums (D. marsupialis) was as high as 12/37 (32.4\%), concluding that this animal is an important reservoir of L. infantum. Additionally, Travi et al. (1998a) [7] studying the natural infection of $D$. marsupialis in both undisturbed and degraded dry forest in northern Colombia, observed respectively that $3 / 21$ (14.3\%) and $13 / 137$ (9.5\%) of those animals were infected. Cabrera et al. (2003) [3], studying an opossum population in Rio de Janeiro, Brazil, observed that $29 \%$ were positive with L. infantum by IFA, and the authors considered that the presence of opossums represented an important risk factor for the transmission of leishmaniasis.

Finally, Adler et al. (2003) [8], examining the feeding success of Lutzomyia evansi, who experimentally exposed small mammal hosts in an endemic focus in northern Colombia, concluded that Didelphis marsupialis is one of the species of wild mammals with the greatest impact on transmission of L. infantum.

Despite the considered importance of the opossums as reservoirs of Leishmania infantum as reflected by: high percentage of natural infections, species predominance, high adaptability to peridomiciliar habitats, vector attractiveness, concomitancy with human cases as well as the capacity to act as a link between sylvatic and domestic environment [3], there is only one record related to the direct observation of parasites in the tissues of $D$. marsupialis from Colombia with natural infection [6].

In addition, it is very important to understand the specific role of each species of the genus Didelphis on AVL epidemiology, considering that they present a wide geographical distribution on the Americas coincident with several countries where AVL is endemic. Until now, only two species of Didelphis have been studied.

In the present paper, we report for the first time, the observation of amastigotes in tissues of Didelphis aurita naturally infected with $L$. infantum trapped in an urban area of Rio de Janeiro state, Brazil. We also discuss some aspects related to the relationship between $L$. infantum and the geographical distribution of some species of the genus Didelphis.

\section{Methods}

\section{Study area}

The opossums studied were caught in Barra de Guaratiba, Rio de Janeiro a peri-urban endemic area for AVL. Several notified human cases have been reported from this area with a high animal host seroprevalence in dogs, cats and opossum [3,9] Barra de Guaratiba (23 03' 57" S; $\left.43^{\circ} 34^{\prime} 00^{\prime \prime} \mathrm{W}\right)$ is a strip of land localized between the Atlantic Ocean and the mountains of Pedra Branca, a massif belonging to Serra do Mar in Rio de Janeiro State. The climate is tropical, with an annual average temperature of $27.5{ }^{\circ} \mathrm{C}$ and rainfall of $1400 \mathrm{~mm}$.

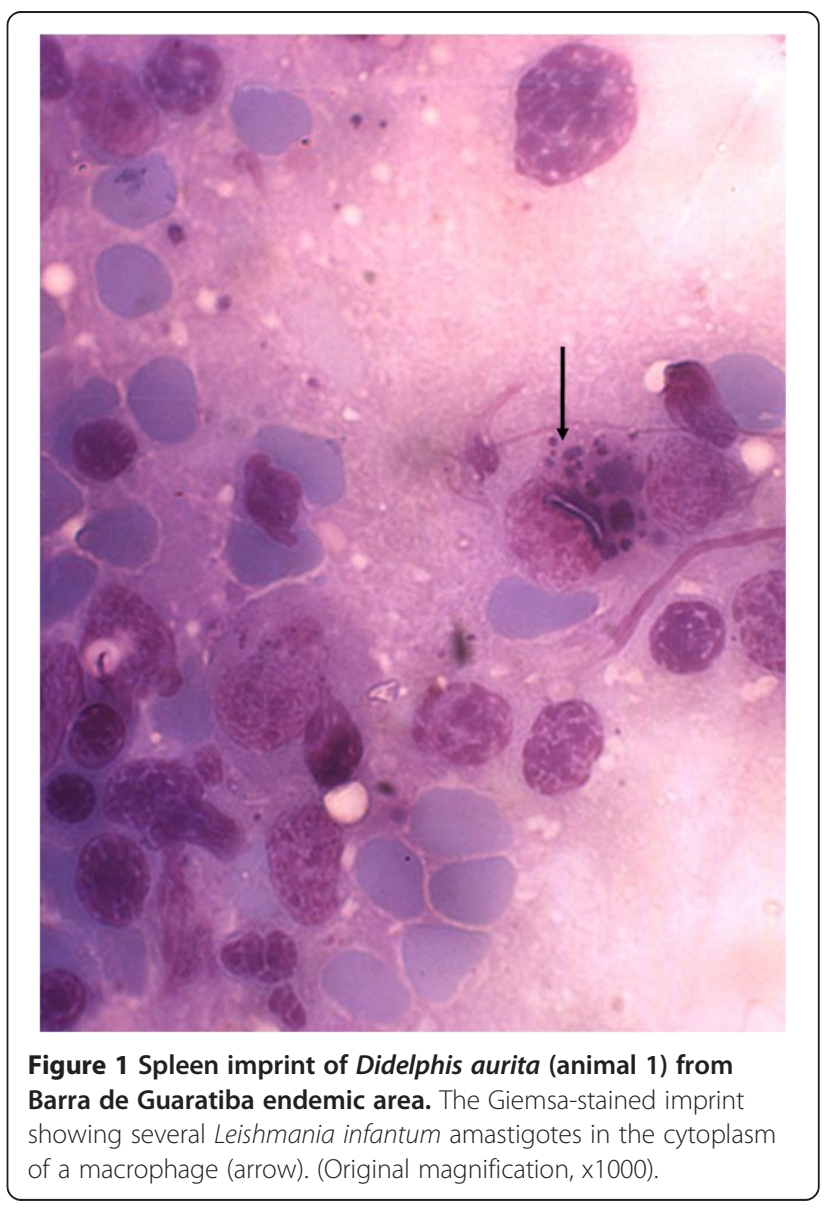


Table 1 Results of the three positive opossums by dipstick tests, imprints, PCR and macroscopic findings on the necropsy

\begin{tabular}{ccccccc}
\hline Animal & Dipstick & \multicolumn{2}{c}{ Imprint } & PCR & Necropsy \\
\cline { 3 - 4 } & & Spleen & lymph node & & \\
\hline $\mathbf{1}$ & + & + & - & + & - \\
$\mathbf{2}$ & + & + & + & + & spleen hypertrophy \\
$\mathbf{3}$ & + & + & - & + & - \\
\hline
\end{tabular}

Secondary Atlantic Forest altered by anthropic action covers the mountain slopes.

\section{Opossum populations}

Forty-eight opossums were captured by wire traps (Tomahawk), thirty were caught in a mangrove area and the rest of them in a forest area nearby some residentialyards. Blood was collected by puncture of the femoral artery, allowed to clot and serum separated by centrifugation and stored at $-20{ }^{\circ} \mathrm{C}$ until use. The opossums were killed with an overdose of Thiopental sodium (10-25 mg/kg, i.v.) and potassium chloride $(100 \mathrm{mg} / \mathrm{kg}$, IV). All the animals used in this study were identified in accordance to Cerqueira (2007) [10].

At necropsy, macroscopic alterations were examined and samples from liver, spleen, lymph nodes, ear, abdominal skin, scent glands and bone marrow were collected for parasitological and molecular diagnoses. For the imprints, three samples of each tissues were fixed with methanol and stained with May Grünwald-Giemsa (SIG$\mathrm{MA}^{\circledR}$ ). The dilution was two drops of Giemsa stain for each $\mathrm{ml}$ of distilled water and a staining time of $40 \mathrm{~min}$ utes was used.

All animals used in this study were in accordance with guidelines defined by the Committee of Ethics in Animal Experimentation of the Oswaldo Cruz Foundation Rio de Janeiro, Brazil and permission for trapping was granted by a license of Instituto Brasileiro do Meio Ambiente e dos Recursos Naturais Renováveis (IBAMA).

\section{Dipstick test}

The Dipstick Test (kit Rapidest Leishmania ${ }^{\circledR}$ ) was carried out from blood samples, according to the manufacturer's instructions. The dipsticks were briefly placed into $10 \mu \mathrm{l}$ of serum. After $10 \mathrm{~min}$ a red control line and, if positive, a second line appeared on the test field. The test is based on a combination of protein-A colloidal gold conjugate and rk39 Leishmania antigen to detect anti-Leishmania antibody in serum or plasma.

\section{PCR and dot blot analysis}

For DNA isolation and PCR analysis, opossums' spleen and liver samples, from positive Dipstick tested animals, were mixed with a solution of Guanidine-EDTA in a proportion of 1:1 and after 24 hours the mixture was boiled for 1 minute and kept at $4{ }^{\circ} \mathrm{C}$ until DNA extraction. Total DNA obtained from cultured $L$. (L.) infantum promastigotes (MHOM/BR/1974/PP75) were used as a positive control.

For the PCR multiplex assay, one primer pair was used. The primers [5'-GGCCCACTATATTACACCAAC CCC-3' and 5' -GGGGTAGGGGCGTTCTGCGAA-3'] were employed to amplify the conserved region of kinetoplastic minicircle DNA from Leishmania spp [11]. The reactions were carried out in a final volume of $100 \mu \mathrm{l}$ containing $1 \times$ Taq polymerase buffer (Applied Biosystems, Foster City, CA, USA), $4.5 \mathrm{mM} \mathrm{MgCl} 2,200 \mu \mathrm{M}$ of each dNTP (Invitrogen), $0.2 \mu \mathrm{M}$ of each primer, $1.25 \mathrm{U}$ Taq Gold DNA polymerase (Applied Biosystems) and $10 \mu \mathrm{L}$ DNA sample. The mixture was incubated in a PerkinElmer thermocycler (GeneAmp PCR System 9600; Applied Biosystems, Foster City, CA, USA). Ten microlitres of the amplification reaction product was resolved in $2 \%$ agarose gel electrophoresis and visualised under UV transillumination. The amplified products were also analysed by dot blot hybridization using a L. infantum-specific biotinylated probe [5`AAAAATGGGTGCAGAAAT 3`] [12]. Hybridization reactions were revealed using Luminol reagent (Santa Cruz Biotechnology). Each experiment included both negative and positive controls.

\section{Results}

\section{Necropsy and dipstick tests}

Considering the analysis of both the imprint and sera samples assayed on Dipstick Tests, among the thirty animals trapped in the mangrove area, all of them were negative. Otherwise, it was observed that three out of 18 opossums caught close to the forest were positive (16.6\%). At macroscopic examination one out of eighteen animals presented alterations compatible with spleen

\begin{tabular}{lllll}
\hline 1 & 2 & 4 & 6 \\
Figure 2 Hybridization with specific probe for Leishmania infantum. Amplified products from specific primers for the Leishmania (120 pb). (1) \\
negative control, (3), (4) and (5) opossums positive samples, (2) and (6) opossums negative samples, (7) positive control. All samples studied were \\
in duplicate.
\end{tabular}


hypertrophy. All three positive animals presented amastigotes in spleen and in one of them the parasites were also observed in a submandibular lymph node. In the spleen (Figure 1) as well as in the lymph nodes, the parasites were observed in general inside macrophages with the cells showing the parasitophorous vacuoles containing easily detectable amastigotes (Table 1).

\section{PCR and dot blot}

For PCR and Dot Blot sample studies, in the visualization of the amplification products in agarose gel of the three opossums the samples were positive, amplifying a product of $120 \mathrm{pb}$, corresponding to the conserved kDNA region of Leishmania sp. After hybridization of this amplified product with a specific probe for L. infantum, the positive samples were confirmed as Leishmania infantum and controls maintained negative (Figure 2).

\section{Discussion}

In early studies, the role of Didelphis albiventris as a reservoir of $L$. infantum was unclear due to low rate of natural infections and discreet histopathological findings $[4,13]$. Subsequently, works with Didelphis marsupialis showed that it can exhibit a different infection pattern, with significant tissue parasitism and tissue lesions as well as high percentages of natural infections [3,5,13-15].

In our results, $D$. aurita showed a very similar infection profile as compared to $D$. marsupialis, so it is likely that black-eared opossums represented by those species could exhibit a higher susceptibility to L.infantum infections differently to the white-eared opossum, $D$. albiventris. This hypothesis is based on the fact that the genetic background at the inter-species level could influence the susceptibility to a determined parasite, as already observed in murine models for Leishmania [7,16,17].

Taking into account the several records related to natural infections of opossums with L.infantum in the New World, if we consider the six extant species of the genus Didelphis that are: D.virginiana, D.pernigra, D.imperfecta, D.aurita, D.albiventris and D.marsupialis $[10,18,19]$, apparently only the last two have been described as natural hosts of the parasite, indicating a need for studies that evaluate the role of other species in the epidemiology of AVL $[5,13-15,20]$. Nevertheless, a very important point to be considered is the need of a correct classification of the species investigated, because the host's behavior and its interplay with the habitat are key factors that determine the epidemiological characteristics of the AVL in a specific place.

Considering specifically the descriptions about the participation of didelphids in the epidemiology of leishmaniasis, we could mention some taxonomic misinterpretations where the authors described D. marsupialis as a host of Leishmania, respectively in Rio de Janeiro and the metropolitan region of Belo Horizonte, Minas Gerais, Brazil $[3,21]$. In fact, it is very unlikely that any specimens of $D$. marsupialis have been captured in these areas, as, based on the last reviews of the genus Didelphis $[10,18,19]$. this species is more often related to the Amazon region, thus, it is probable that they worked with $D$. aurita which occurs in southeastern Brazil and it is morphologically very similar to D. marsupialis.

\section{Conclusions}

The high complexity of the AVL eco-epidemiology related to the geographical distribution of the several species that compound the genus Didelphis in South America have resulted in some mistakes, thus in the present paper we attempted to argue the probable role of some species of opossums correlated to their natural habitats, contributing at least in part to the elucidation of AVL ecology in relation to this group of marsupial hosts.

\section{Competing interests}

The authors declare that they have no competing interests.

\section{Acknowledgments}

This work received financial support from CNPq/Fiocruz - Papes IV, Faperj APQ1 and from Instituto Oswaldo Cruz. The authors wish to thank Dr. Rui Cerqueira for the contribution related to the opossum species and their geographical distribution. To Dr. Daniel Bray who reviewed the English. We are also grateful for the technical support of Camila Melo Marques de Jesus and Claudia Dias de Souza Cândido.

\section{Author details}

${ }^{1}$ Núcleo Jacarepaguá, Instituto Oswaldo Cruz/Fiocruz, Rio de Janeiro, Brazil. 'Laboratório de Bioquímica de Proteínas e Peptídeos, Instituto Oswaldo Cruz/ Fiocruz, Rio de Janeiro, Brazil. ${ }^{3}$ Laboratório de Bioquímica Molecular de Doenças Endêmicas, Instituto Oswaldo Cruz/Fiocruz, Rio de Janeiro, Brazil. ${ }^{4}$ Laboratório de Bioquímica e Fisiologia de Insetos, Instituto Oswaldo Cruz/Fiocruz, Avenida Brasil, 4365, Rio de Janeiro, RJ CEP 21045-900, Brazil.

\section{Authors' contributions}

JCAC conceived of the study, besides acquisition, analysis and interpretation of data; drafting the article or revising it critically for important intellectual content. AVMS participated in the design of the study, analysis and interpretation of data. DPP carried out the molecular genetic studies. RPB helped to draft the manuscript and revised it critically for important intellectual content. All authors read and approved the final manuscript.

Received: 24 January 2012 Accepted: 7 June 2012

Published: 7 June 2012

\section{References}

1. Deane LM, Deane MP: Observações preliminares sobre a importância comparativa do homem, do cão e da raposa Lycalopex vetulus como reservatórios da $L$. donovani em área endêmica de calazar no Ceará. Hosp 1955, 48:61-70.

2. Lainson R, Rangel EF: Lutzomyia longipalpis and the eco-epidemiology of American visceral leishmaniasis, with particular reference to Brazil: a review. Mem Inst Oswaldo Cruz 2005, 100:811-827.

3. Cabrera MAA, De Paula AA, Camacho LAB, Marzochi CA, Aguiar GM, Xavier SC, Silva AVM, Jansen AM: Canine Visceral Leishmaniasis in Barra de Guaratiba, Rio de Janeiro, Brazil: assessment of some risk factors. Rev Inst Med Trop S Paulo 2003, 45:79-83.

4. Sherlock IA, Miranda JC, Sadigursky M, Grimaldi Júnior G: Natural infection of the opossum Didelphis albiventris (Marsupialia, Didelphidae) with Leishmania donovani, in Brazil. Mem Inst Oswaldo Cruz 1984, 79:511. 
5. Sherlock IA, Miranda JC, Sadigursky M, Grimaldi Júnior G: Observações sobre Calazar em Jacobina, Bahia. VI - Investigações sobre reservatórios silvestres e comensais. Rev Soc Bras Med Trop 1988, 21:23-27.

6. Corredor A, Gallego JF, Tesh RB, Morales A, De Carrasquilla CF, Young DG, Kreutzer RD, Boshell J, Palau MT, Caceres E: Epidemiology of visceral leishmaniasis in Colombia. AmJTrop Med Hyg 1989, 40:480-486.

7. Travi BL, Osorio Y, Becerra MT, Adler GH: Dynamics of Leishmania chagasi infection in small mammals of the undisturbed and degraded tropical dry forests of northern Colombia. Trans R Soc Trop Med Hyg 1998, 92:275-278.

8. Adler GH, Becerra MT, Travi BL: Feeding success of Lutzomyia evansi (Diptera: Psychodidae) experimentally exposed to small mammal hosts in an endemic focus of Leishmania chagasi in northern Colombia. Biomedica 2003, 23:396-400.

9. Silva AVM, Cândido CDS, Pereira DP, Brazil RP, Carreira JCA: The first record of American visceral leishmaniasis in domestic cats from Rio de Janeiro, Brazil. Acta Trop 2008, 105:92-94.

10. Cerqueira R: Marsupials Didelphimorphia, Microbiotheria, and Paucituberculata), Xenarthrans (Angulata, Pilosa), Shrews (Soricomorpha), and bats (Chiroptera. In Mammals of South America, Volume 1. Edited by Gardner AL. Chicago: University of Chicago Press; 2007:1-699.

11. Passos VM, Lasmar EB, Gontijo CM, Fernandes O, Degrave W: Natural infection of a domestic cat (Felis domesticus) with Leishmania (Viannia) in the metropolitan region of Belo Horizonte, State of Minas Gerais, Brazil. Mem Inst Oswaldo Cruz 1996, 91:19-20.

12. Francino $O$, Altet $L$, Sánchez-Robert E, Rodriguez A, Solano-Gallego L, Alberola J, Ferrer L, Sánchez A, Roura X: Advantages of real-time PCR assay for diagnosis and monitoring of canine leishmaniosis. Vet Parasitol 2006, 137:214-221.

13. Sherlock IA, Miranda JC, Sadigursky M, Grimaldi Júnior G: Experimental infection of the opossum Didelphis albiventris (Marsupialia, Didelphidae) with Leishmania donovani. Mem Inst Oswaldo Cruz 1988, 83:141.

14. Travi BL, Jaramillo C, Montoya J, Segura I, Zea A, Gonçalves A, Velez ID: Didelphis marsupialis, an important reservoir of Trypanosoma (Schizotrypanum) cruzi and Leishmania (Leishmania) chagasi in Colombia. AmJTrop Med Hyg 1994, 50:557-565.

15. Travi BL, Osorio Y, Guarin N, Cadena H: Leishmania (Leishmania) chagasi: clinical and parasitological observations in experimentally infected Didelphis marsupialis, reservoir of New World visceral leishmaniasis. Exp Parasitol 1998, 88:73-75.

16. Blackwell JM: Genetic susceptibility to leishmanial infections: studies in mice and man. Parasitol 1996, 112:67-74.

17. Travi BL, Arteaga LT, Leon AP, Adler GH: Susceptibility of spiny rats (Proechimys semispinosus) to Leishmania (Viannia) panamensis and Leishmania (Leishmania) chagasi. Mem Inst Oswaldo Cruz 2002, 97:887-892.

18. Cerqueira R, Lemos B: Morphometric differentiation between Neotropical black-eared opossums, Didelphis marsupialis and Didelphis aurita (Didelphimorphia, Didelphidae). Mammalia 2000, 64:319-327.

19. Lemos B, Cerqueira R: Morphological differentiation in the white-eared opossum group (Didelphidae: Didelphis). J Mammal 2002, 83:354-369.

20. Corredor A, Gallego JF, Tesh RB, Peláez D, Diaz A, Montilla M, Paláu MT: Didelphis marsupialis, an apparent wild reservoir of Leishmania donovani chagasi in Colombia. South America. Trans R Soc Trop Med Hyg 1989, 83:195.

21. Schallig HDFH, Silva ES, Van Der Meide W, Schoone GJ, Gontijo CMF: Didelphis marsupialis (common Opossum): A potential reservoir host for zoonotic leishmaniasis in the metropolitan region of Belo Horizonte (Minas Gerais, Brazil). Vector Borne Zoonotic Dis 2007, 7:387-393.

doi:10.1186/1756-3305-5-111

Cite this article as: Carreira et al:: Natural infection of Didelphis aurita

(Mammalia: Marsupialia) with Leishmania infantum in Brazil. Parasites \& Vectors 2012 5:111.

\section{Submit your next manuscript to BioMed Central and take full advantage of:}

- Convenient online submission

- Thorough peer review

- No space constraints or color figure charges

- Immediate publication on acceptance

- Inclusion in PubMed, CAS, Scopus and Google Scholar

- Research which is freely available for redistribution

Submit your manuscript at www.biomedcentral.com/submit
C Biomed Central 